Page I19. Rudiments of the wisdom teeth are not usually present in either upper or lower jaw at birth.

Page 132. Fig. 136 could be made much more useful if it showed that the submaxillary ganglion is always found where the lingual nerve crosses the submaxillary duct.

Page 137. No mention is made of the important relation of the external laryngeal nerve to the lateral lobe of the thyroid gland.

Page 623. The statement that "the perinaeal body does not play an important part in the support of the pelvic contents' requires revision. This very useful structure is the common point of insertion of perinaeal muscles, including the pelvic diaphragm, and as a 'point-d'appri' does play an indirect, though vital part, in the support of pelvic viscera.

Page 193. The description of the levator ani here given very much needs correlating with the account of the same muscle given.on page 100.

Page 607. The statement that in spondylolisthesis 'cure cannot be effected' now requires some modification.

Page 558. Recognition of second lumbar ganglion. The ' 2 nd and 3 rd ganglia' should obviously read ' 3 rd and 4 th.'

On page 162, line 14, and page 715, Fig. 721, minor misspellings need correction.

The black and white drawings of Dr. E. A. Thomas continue in increasing number to illustrate the letter-press, and though some may be of doubtful value and too diagrammatic, perhaps, to give the reader a true visual impression of the actual condition, most of them are helpful and are executed with discerning ingenuity and skill.

The above friendly criticisms are made in the hope that this valuable member of the "Synopsis Series' may continue to flourish and even increase its well-deserr $\mathrm{d}$ popularity in future editions.

J.K.

\section{BRITISH ENCYCLOPAEDIA OF MEDICAL PRACTICE}

\section{Vols. 3 and 4}

Edited by The RT. Hon. LORD HoRder, G.C.V.O., M.D., F.R.C.P. Vol. 3: Pp. xvi +707 , with 95 illustrations, and is coloured plates. Vol. 4: Pp. xvi +746 , with I $_{31}$ illustrations. London: Butterworth and Co. 1930. £3 each volume.

There are many changes in the new edition of these two volumes. On turning over the pages one is struck at once by the fact that the illustrations are more numerous and that many more coloured plates of excellent quality have been included. The latter will be welcomed, especially those depicting diseases of the skin and eye.

More than half the total chapters have been recast by new contributors most of whom are already well known by their writing. But some of the chapters by younger newcomers are also of a high order of excellence. One might mention, particularly, the sections on Dyspareunia and Dysmenorrhoea by Mr. J. McClure Brown. The reviewer notes with regret the absence of Dr. F. R. M. Walshe's lively pen from the present work, $\frac{\Phi}{2}$ but hopes that it may appear once more in later $C$ volumes.

An important and much needed section on Cor $\stackrel{\vec{F}}{\vec{\rho}}$ Pulmonale by Dr. Paul Wood appears for the first time in Volume 3 , which also includes new chapters $\frac{1}{\circ}$ on Bursitis and Coccidioimyces. The sections of $\overline{\bar{c}}$. Bronzing of the Skin, Cancer, Canities (which, $\underset{\mathbb{D}}{\vec{D}}$ incidentally, means greying of the hair) and Chordoma have been omitted from the present $\%$ edition without great loss.

The only new subject included in Volume 4 is. Dr. E. G. L. Bywaters' chapter on Crush Syndrome. $\vec{\omega}$ Perhaps the author's modesty and reluctance too emphasize his own contributions to our knowledge $\vec{\square}$ on this important subject have resulted in an un- 3 necessarily brief and contracted account. The chapters in the old edition on Cramp, Sudden. Death, Drug Addiction and Care of the Dying have ${ }_{-}$ been omitted from the present work. No doubt. some sacrifice must be made to allow room for new matter, but the omission of all these sections is re- $\rightarrow$ gretted. Cramp is a common complaint and,응 although the subject of recent work in the UnitedStates, many doctors continue to be delightfullyes vague about its causes and treatment. Practitioners, $\mathbb{D}$ called upon to perform the occasional coroner's $\mathbb{D}$ autopsy, like to be reminded of the possible causes $9 f^{3}$ sudden death in the difficult case. Drug addiction is probably included in the appropriate sections psychological medicine, but the surprising comfusion in the index of Volume 3 , which has pases. missing or reduplicated, made this point difficult to check.

Although care of the dying patient depends a great deal on the personality and skill of the doctor, littleo emphasis is placed upon it in medical training, while

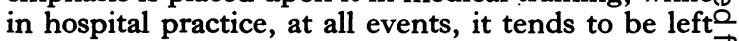
to the nursing staff. It is our loss that Professoro $\overrightarrow{\overrightarrow{0}}$ John Ryle is no longer with us to write a worthy section on this important subject.

\section{OCCUPATIONAL FACTORS IN THE AETIOLOGY OF GASTRIC AND DUODENAL ULCERS}

\section{M.R.C. Special Report Series No. 276}

By Richard Doll, M.D., M.R.C.P., and F. Avery Jones, M.D., F.R.C.P. Pp. 96. London:
H.M.S.O. I95I. 2s. 6d.

This is a statistical enquiry into the occupationato factors in the aetiology of gastric and duodenal ulcer. A population of over 6,000 individuals earn- $N$ ing their livings in various ways has been studied. They were sub-divided into those with no dyspepsia, $N$ those with minor dyspepsia and those with majore dyspepsia. The last group contained all witho recognized ulcer, or with suspected ulcer, and aftero they had been interviewed by one of the authors, they were finally re-classified into proved peptices ulcer, presumptive ulcer, other dyspepsia and no dyspepsia. Radiological investigation was carried out when necessary to establish a diagnosis. 